\title{
Use of optical coherence tomography in orthodontics
}

\author{
STELIAN-MIHAI-SEVER PETRESCU ${ }^{1 *}$, MIHAELA JANA ȚUCULINA ${ }^{1}$, EUGEN OSIAC $^{1}$, ADRIAN CAMEN $^{1}$, \\ ALEX IOAN SĂLAN ${ }^{1 *}$, FELICIA ILEANA MĂRĂȘESCU ${ }^{1}$, ANDREEA GABRIELA NICOLA ${ }^{1}$, \\ EDWIN SEVER BECHIR ${ }^{2 *}$ and IONELA TEODORA DASCĂLU ${ }^{1}$ \\ ${ }^{1}$ Faculty of Dentistry, University of Medicine and Pharmacy of Craiova, 200349 Craiova; ${ }^{2}$ Faculty of Dentistry, \\ University of Medicine and Pharmacy of Târgu Mureș, 540142 Târgu Mureș, Romania
}

Received August 6, 2021; Accepted September 7, 2021

DOI: 10.3892/etm.2021.10859

\begin{abstract}
Optical coherence tomography (OCT) is a modern imaging method with applicability in orthodontics. In recent years, there has been an increasing trend in the use of ceramic brackets. The aim of the present study was to investigate the effects of bonding metallic and ceramic brackets on tooth enamel, using optical coherence tomography. For this purpose, 20 permanent teeth we bonded and were subsequently debonded using a side cutter or anterior bracket removal pliers. Using the OCT technique, the enamel, the amount of adhesive remaining and the bracket fragments remaining on the tooth surface were analyzed following the debonding procedure. It was demonstrated that enamel cracks were present only in the samples bonded with ceramic brackets. At the same time, it was noted that the type of pliers did not affect the incidence and extent of damage to the enamel. The type of debonding technique (using the side cutter or the anterior removal pliers) used did not markedly affect the amount of adhesive remaining on the teeth. Thus, as demonstrated herein, by analyzing the enamel structure through the use of OCT, the quality of the processes and the materials used for manufacturing brackets can be increased.
\end{abstract}

\section{Introduction}

Optical coherence tomography (OCT) can be defined as a modern imaging investigation technique. This technique is effective in visualizing the differences in the optical properties of tissues. OCT has both optical absorption and optical reflection properties (1).

Correspondence to: Professor Mihaela Jana Țuculină or Dr Adrian Camen, Faculty of Dentistry, University of Medicine and Pharmacy of Craiova, 2-4 Petru Rareș Street, 200349 Craiova, Romania E-mail: mtuculina@yahoo.com

E-mail: adrian.camen@umfcv.ro

${ }^{*}$ Contributed equally

Key words: optical coherence tomography, enamel cracks, brackets, adhesive, debonding, pliers
OCT was introduced into the medical field $>20$ years ago and was initially used for structural and functional investigations of the eye by ophthalmologists (2-4). The use of OCT technologies has increased in recent years in various medical domains, such as gastroenterology, dermatology and neurology (5-12). Recently, OCT has been used in dental medicine and particularly in orthodontics. There are a multitude of uses for OCT in the field of dentistry, such as for the anatomical examination of dental and periodontal structures, for the qualitative and quantitative evaluation of the resins used in the bonding procedure, for the examination of the biofilm formed around the brackets, and for the evaluation of periodontal ligament responses to various orthodontic forces generated during treatment (13-16).

The most crucial advancements in orthodontics were made with the introduction of acid etching, followed by the direct bonding of the brackets on the enamel surface, using an epoxy resin. This technique was described by Newman in 1965 (17). Currently, the adhesive systems used in orthodontics are based on Bowen's bisphenol A-glycidyl methacrylate (Bis-GMA) resin. This resin is available in a wide variety of viscosities for easy penetration into the etched enamel surfaces (18).

At the end of the orthodontic treatment period with fixed appliances, a crucial step is the bracket debonding procedure. During this step, particular attention should be paid to the removal of all adhesive resin from the enamel surface. The orthodontist should also aim to restore the tooth surface to its pre-treatment condition as much as possible.

Bracket debonding is one of several causes of iatrogenic damage to enamel. The evaluations of this procedure are commonly performed using an optical microscope; however, this method ensures that only the enamel surface is analyzed. OCT is a high-resolution optical technique that allows the minimally invasive visualization of near-surface alterations in complex tissues. The applications of OCT in dental medicine are related to both hard and soft tissue analysis.

Based on low coherence interferometry using broadband light, the OCT investigation can provide real-time structural images of the enamel and of the soft parts. Currently, this imaging technique can be used to detect the morphological changes of oral tissues in vivo. It is also applicable in the diagnosis of early tooth lesions, in assessing the progression of periodontal disease and in detecting oral cancer $(19,20)$. 


\section{Materials and methods}

The present study was approved by the Ethics Committee of the University of Medicine and Pharmacy of Craiova, Romania (approval reference no. 72/07.09.2020), in accordance with the ethical guidelines for research with human participants of the University of Medicine and Pharmacy of Craiova, Romania. Written informed consent was obtained from all subjects involved in the study. The present study was performed on a total of 20 permanent teeth extracted at the Oral and Maxillofacial Surgery Clinic of the Clinical Emergency County Hospital of Craiova, Romania. These teeth did not exhibit carious lesions, attrition/abrasion, cracks, or staining (when examined visually and using OCT).

The extracted teeth used in the present study were rinsed with water and then disinfected with $10 \% \mathrm{H}_{2} \mathrm{O}_{2}$ for $10 \mathrm{~min}$. Following the disinfection process, each tooth sample was scaled and polished to remove gingival tissue. To avoid desiccation, the samples were maintained in deionized water until the brackets were bonded. The present study used metallic brackets/Legend medium (GC Orthodontics, Inc.) and ceramic brackets/Ceramic-1 (Changsha Denxy Technology Co., Ltd.), all with a similar mesh. The teeth were randomly divided into four groups ( $\mathrm{n}=5$ per group) depending on the type of bonded bracket and the pliers used for debonding.

Prior to the bonding procedure, the samples were removed from the solution and dried using paper towels. The buccal surface of each tooth was examined using the OCT system manufactured by Thorlabs (OCS1300SS), powered by a swept laser source with a central wavelength of $1,310 \mathrm{~nm}$, a spectral bandwidth of $100 \mathrm{~nm}$ and an average power of $12 \mathrm{~mW}$. The device was used for 2D and 3D scans, thus ruling out the possibility of tooth samples with enamel damage.

The enamel surfaces were etched with Trulock ${ }^{\mathrm{TM}}$ Etchant Gel (Rocky Mountain Orthodontics) containing 37\% phosphoric acid for $20 \mathrm{sec}$, and then rinsed with water for $10 \mathrm{sec}$ and air-dried. The bonding procedure was performed using Trulock Light Activated Adhesive (Rocky Mountain Orthodontics), following the manufacturer's instructions. The adhesive was light-cured for $20 \mathrm{sec}$ from the incisal/occlusal and cervical sides of the bracket using a $3 \mathrm{M}^{\mathrm{TM}}$ Elipar ${ }^{\mathrm{TM}}$ DeepCure-L LED Curing Light (1,470 mW/cm²; 3M Science) (Fig. 1).

Following the bonding procedure, the tooth samples were stored in deionized water for $24 \mathrm{~h}$. The debonding procedure was performed $24 \mathrm{~h}$ after bonding using two different pliers: A side cutter (model T00552, Rocky Mountain Orthodontics) and anterior bracket removal pliers (model 678-219, Hu-Friedy Mfg. Co., LLC). All these procedures were performed by the same operator. Although there are various methods regarding the use of these pliers, the debonding phase was performed following a standardized technique.

The side cutter was positioned diagonally at the bracket base and at the incisal/occlusal and cervical level. The bracket was removed by gently squeezing the pliers and performing an additional clockwise rotational movement. The anterior bracket removal pliers were applied by gripping under the bracket wings at the bracket-enamel interface. By squeezing and tilting the pliers downward, a rotational axis was generated at the lower edge of the bracket, thus detaching it from the enamel surface.
Following the debonding procedure, the teeth were fixed in dental silicone (Optosil Comfort Putty, Kulzer GmbH) and positioned for examination using a stereomicroscope manufactured by Nikon (SMZ745T), equipped with NIS-A AMEAS and NIS-A EDF software (version 4.50) for image and data acquisition and processing.

Subsequently, the samples were also fixed in dental silicone and positioned so that the OCT light beam could fall perpendicularly on the debonded surfaces. Thus, the samples were re-examined using the OCT system, and 2D and 3D images of the surfaces involved were obtained.

The present study used a design that allowed the visualization of the tooth surface at different angles in order to detect enamel cracks, the amount of adhesive remaining and bracket fragments resulting from the debonding procedure. At the same time, healthy teeth surfaces were included as controls for the experiment. Tooth surfaces imaged using the OCT system at widths of $10 \mathrm{~mm}$ with a distance of $10 \mathrm{~mm}$ and a depth of $3 \mathrm{~mm}$ were sampled. The obtained images were processed using ImageJ software (version 1.8.0, National Institutes of Health), which is an open access program.

\section{Results}

Following the OCT examination, 512 images were obtained for each tooth surface subjected to the debonding procedure. From these, the most representative images were selected, both for the teeth bonded with metallic brackets and for those bonded with ceramic brackets. Those images in which the OCT image was well outlined to be relevant were considered, given that the OCT beam did not always fall perpendicular due to the convexities of the dental surfaces (Fig. 2).

As illustrated in Fig. 2A, the impression left by the sole of the metallic bracket on the surface of the adhesive and small areas where the adhesive came off with the bracket were noted. It was also noted that the adhesive came off almost completely with the ceramic bracket and some adhesive fragments were observed in the areas corresponding to the periphery of the bracket (Fig. 2B).

Following the processing of all the data obtained in the study, it was noted that the metallic brackets generated a larger amount of remaining adhesive on the enamel surfaces compared with that on the ceramic surfaces (Fig. 3). It was observed that cracks appeared only at the tooth surfaces bonded with ceramic brackets and that the type of pliers used for debonding did not influence the incidence and extent of enamel damage. In addition, the OCT images assisted in the evaluation of the size and orientation of the enamel cracks.

As shown in Fig. 3A and C, it was observed that a large amount of the adhesive used for the bonding procedure remained on the enamel surface after bracket debonding. Although the sole of the metallic brackets has a mesh in order to increase mechanical retention, the adhesive adhered more effectively to the enamel surface. In the OCT images, the irregular surface of the adhesive which remained after bracket debonding was observed. The debonding of metallic brackets from dental surfaces does not cause cracks; however, it generates larger amounts of adhesive remnant. This increases the risk of damage to the enamel during conventional adhesive removal techniques with tungsten carbide burs. 

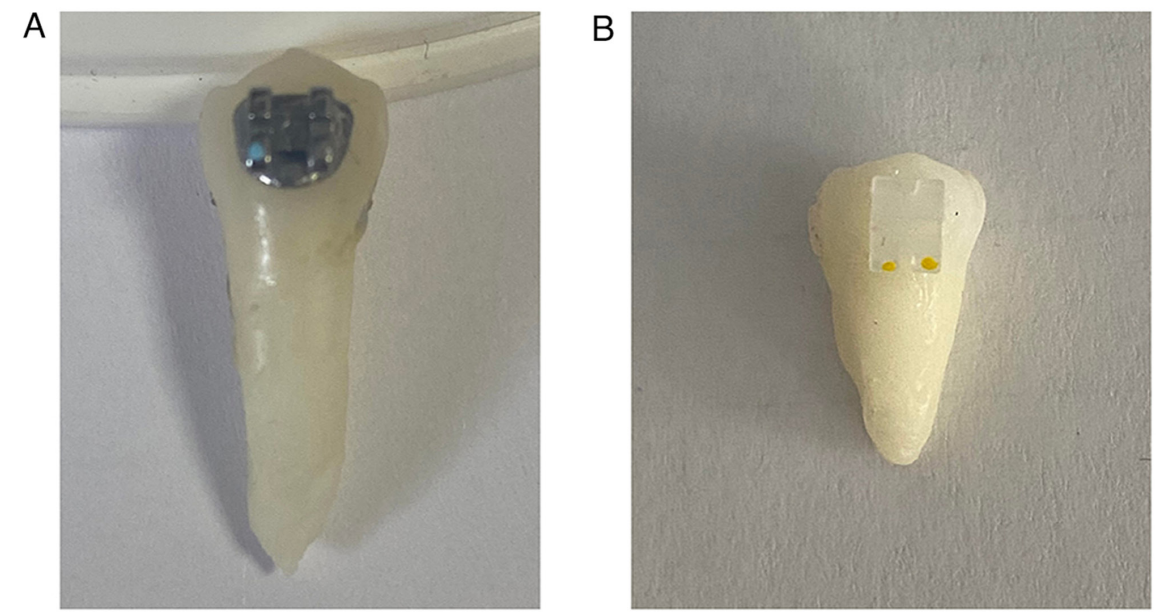

Figure 1. Macroscopic images (magnification, x2.50) of a tooth bonded with a (A) metallic bracket and (B) ceramic bracket.
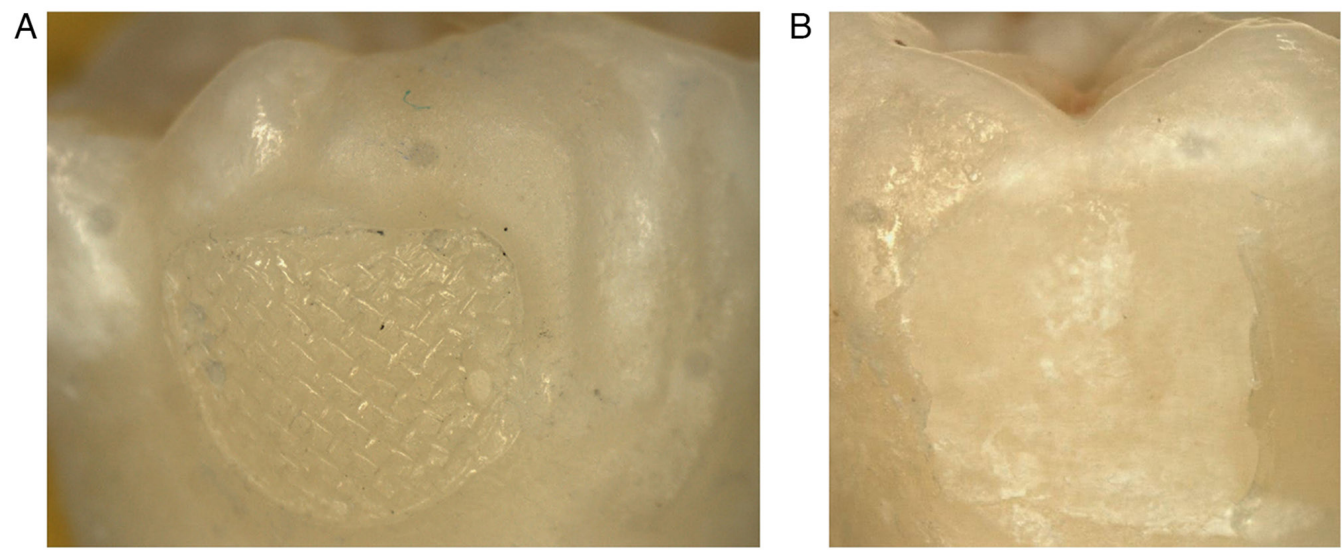

Figure 2. Stereomicroscope imaging (magnification, x30) of the buccal area following the debonding procedure of a (A) metallic bracket and (B) ceramic bracket.

As shown in Fig. 3B and D, cracks on the enamel surface and small amounts of adhesive remnants were noted. The aspects that were observed following the debonding technique highlighted the strong adhering ability of the adhesive to the dental surfaces. As regards the ceramic brackets, the adhesive adhered more effectively to the mesh from their soles as compared to that of the metallic ones. The debonding procedure generated marked detachment forces, causing enamel cracks.

Following the debonding procedure, only fragments of ceramic brackets remained on the enamel surface. It was found that the side cutter generated fractures of the ceramic brackets more frequently than the anterior bracket removal pliers. Both pliers used in the present experiment generated variable amounts of remaining adhesive on the enamel surface.

\section{Discussion}

OCT is a tomographic imaging procedure capable of reproducing high-resolution sectional images of the internal architecture of materials and tissues (1-2 mm depth). With the aid of the OCT technique, images of both normal and pathological hard dental structures can be examined, and the quality of various types of dental treatments can be investigated $(21,22)$. This imaging technique has an increased sensitivity compared with other investigative methods used for this purpose (23).

The majority of studies on the changes of hard dental tissues associated with fixed orthodontic therapy have been performed in vitro on teeth extracted from bovines or humans using scanning electron microscopy, surface profilometry and laser fluorescence (24-27). These studies prompted the authors to conduct an in vitro study on the structural changes caused by the bracket debonding procedure. However, studies conducted using OCT technology are limited. The resolutions (for air) of the OCT system used in the present study were $12 \mu \mathrm{m}$ for axial and $15 \mu \mathrm{m}$ for lateral resolutions. The system allowed for the analysis of a sample of $10 \times 10 \times 3 \mathrm{~mm}$ (length, width and depth, respectively) or $1,024 \times 1,024 \times 512$ pixels in approximately $30 \mathrm{sec}$, using a charge-coupled device-type detector $(28,29)$.

As regards the etching of the dental surfaces in order to bond the brackets, the present study used Trulock Etchant Gel, which is effective on both dentin and enamel. This adhesive system is mainly recommended to patients with poor oral hygiene and, implicitly, with enamel demineralization. Over time, these patients have posed real challenges for orthodontists, as the quality of bracket adhesion on such enamel is 

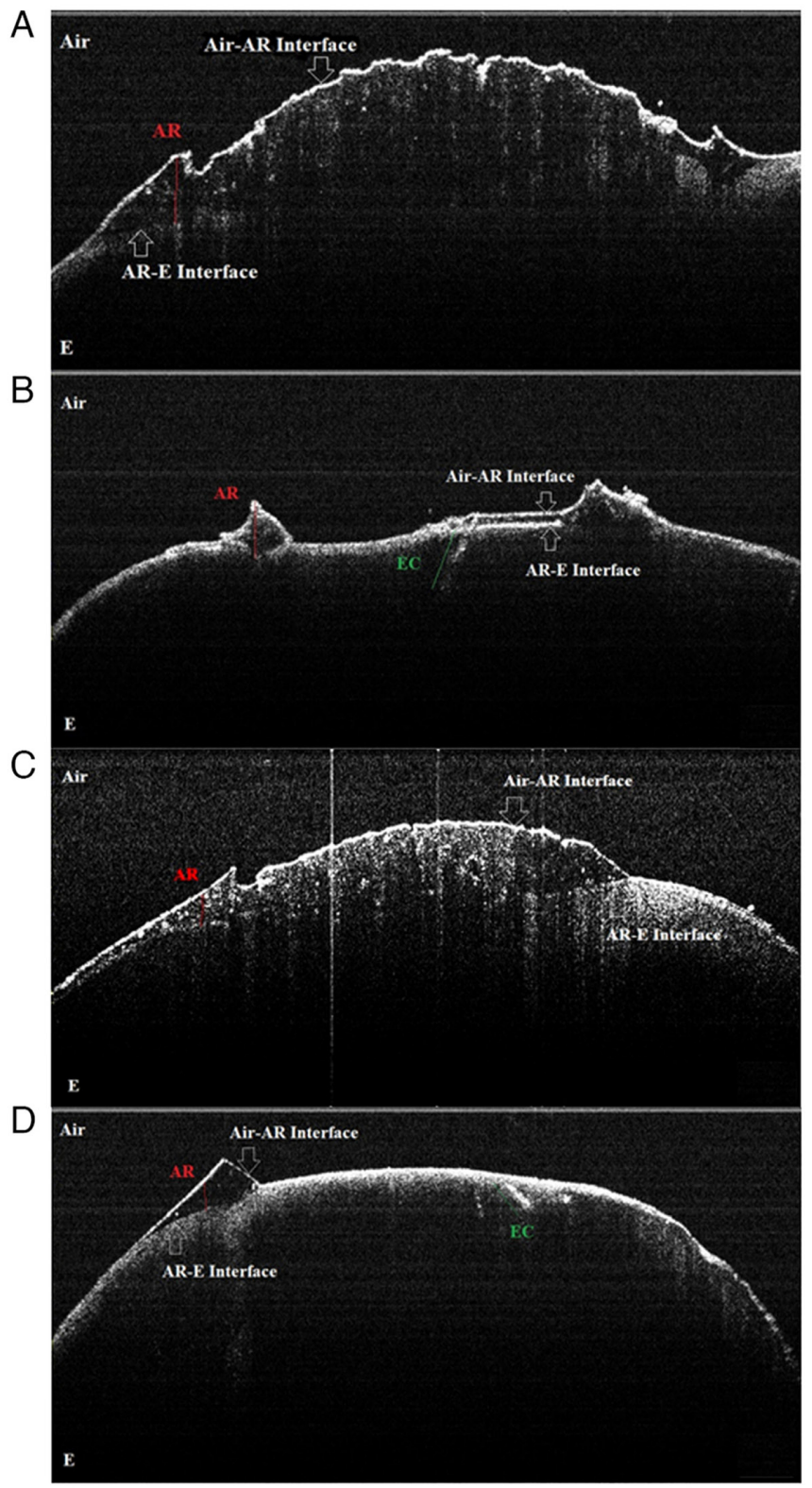

Figure 3. Optical coherence tomography imaging of the buccal area following the debonding procedure of a (A and $\mathrm{C}$ ) metallic bracket and (B and D) ceramic bracket. E, enamel; AR, adhesive remnant; EC, enamel crack.

poor (30). The viscosity of the gel prevents it from leaking from tooth surfaces and can also be easily removed without leaving residue.

For the bonding procedure, Trulock Light Activated Adhesive was selected, as it is single-paste resin-based, thus avoiding the deficiencies caused by conventional two-component systems. The one-component adhesive reduces the risk of accidental bracket debonding and significantly reduces the working time. This adhesive system contains fluoride, which reduces the risk of demineralization and even carious processes around the brackets. These are used in patients with poor oral hygiene, with the fixed orthodontic appliances promoting plaque retention (31).

The integration of fluoride in the adhesive systems for bracket bonding has proven to be an extremely useful measure in preventing dental demineralization following fixed orthodontic treatment (32). The Trulock Light Activated Adhesive is designed to bond metallic, ceramic and plastic brackets. The etching technique (followed by the infiltration of the adhesive resin into the surface layer of the enamel during the bonding procedure) renders it impossible to restore the initial status of the enamel following the completion of orthodontic treatment (33).

Thus, bracket debonding is an orthodontic procedure with an increased risk of damage to the enamel in the form of scratches, cracks or tissue loss. To protect this structure, orthodontists need to use procedures that prevent failures at the enamel-adhesive interface, leaving as much adhesive on the tooth surface as possible. It has been demonstrated that maintaining the structural integrity of the enamel is dependent on the presence of large amounts of remaining adhesive. Modern adhesive technologies seem to be a favorable solution that facilitates orthodontic treatment and yields promising results (34).

The present study used two types of orthodontic pliers: A side cutter and an anterior bracket removal pliers. Both pliers are made of high-quality stainless steel. The side cutter is used for both cutting orthodontic wires and for removing brackets. The anterior bracket removal pliers have a single use, to remove brackets from the anterior zone. These pliers were selected for a variety of reasons: The materials they are composed of, the joint and handle construction and the design of the active parts. The handles are designed to allow an optimal grip. The two arms are joined by a sliding joint, resistant to corrosion, which allows the two active parts to create a perfect alignment. The active parts are narrow and composed of tungsten carbide to facilitate their insertion at the junction between the tooth and the bracket sole. Tungsten carbide is approximately twice as stiff as steel. This property is an important feature of the active parts. These qualities ensure the longevity of the pliers and facilitate the process of bracket debonding. Given that the side cutter is often used to cut orthodontic wires, its active parts are sharpened from those of the anterior bracket removal. For this reason, when using the side cutter for the debonding procedure, the risk of fracturing the ceramic brackets is higher (35). Beginning from this premise, it was decided that the bracket debonding procedure would be performed using a standardized technique in the present study (36). Enamel cracks are difficult to visualize and are often overlooked. They can subsequently lead to the appearance of dental hypersensitivity and pain when chewing, symptoms that dissipate when the stimulus is removed $(37,38)$. The demineralization of the adjacent enamel caused by fixed appliances is an undesirable complication of orthodontic treatment, particularly if it is not detected at an early stage and no remedial action is taken (39).

Previous studies based on OCT imaging have analyzed and compared the quality of the bonding procedure of ceramic and polymeric brackets. The aim of these studies was to evaluate the adhesive film between the bracket sole and the dental surface. Unlike the present study, the OCT analysis of the samples was performed following the bonding technique, observing the defects in the adhesive structure. It was concluded that these gaps may also be the consequence of a human error during the bonding procedure. On the other hand, additional research 
is required to demonstrate the effectiveness of the indirect bonding technique compared with the direct one $(40,41)$.

Another study performing the OCT analysis of the tooth surfaces following bracket debonding concluded that the removal of adhesive remnant increased the roughness of the enamel in accordance with the technique used in this operation. Thus, tungsten carbide burs generated the roughest surfaces, while the use of Adhesive Residue Remover led to the smoothest surfaces (42). It was further demonstrated that the type of tooth on which the bracket is bonded plays an important role (43). Similar to the present study, these studies indicate the importance of OCT in the field of fixed orthodontics $(42,43)$.

A previous clinical study demonstrated that both metallic and ceramic brackets have a similar failure rate (44). Although in vitro studies have indicated that enamel cracks are potential gateways for microorganisms, an infection of the endodontic system is unlikely to occur if the dental pulp is healthy. The risk of pulp necrosis generated by enamel cracks is $3.5 \%$ (45). Previous clinical studies have demonstrated that if a tooth with enamel cracks and reversible pulpitis is diagnosed at an early stage, it can be recovered by applying a micro-prosthesis, with endodontic treatment being necessary in only $20 \%$ of these cases in 6 months $(46,47)$. This finding indicates the importance of the early identification of enamel cracks with the aid of OCT technology, which would facilitate the diagnosis and early treatment of dental hypersensitivity in current practice.

Studies have determined that maintaining the structural integrity of the enamel is closely dependent on the presence of large amounts of adhesive $(19,48)$. In the present study, both pliers used generated variable amounts of adhesive remnants on the enamel surfaces. Thus, the type of pliers did not affect the extent of the enamel damage. The results of the present study are similar to those of other studies $(19,36)$. However, a previous study performed on a small number of samples $(n=6)$ demonstrated that the side cutter led to bond failures at the enamel-adhesive interface, while the anterior bracket removal pliers led to bond failures at the bracket adhesive interface (49).

Ceramic brackets are extremely fragile, and thus a small amount of energy may be sufficient to fracture them (50). From a clinical point of view, the fracture of a ceramic bracket is undesirable, as the presence of bracket fragments on the tooth surface hampers the polishing of the enamel (51). The present study found that the side cutters caused fractures of ceramic brackets more frequently than the anterior bracket removal pliers.

Other studies have also demonstrated that enamel cracks appeared only during the debonding of ceramic brackets, revealing a greater risk of damage from this procedure compared with the debonding of metallic brackets. This aspect can be explained by the fact that the composite system used for the bonding procedure adheres strongly to both surfaces (the enamel and ceramic bracket mesh) $(52,53)$.

Particular attention should be paid to the debonding procedure. Following the bracket removal technique, there should be no adhesive resin remaining on the enamel surface. This step needs to be performed without causing enamel damage. This objective is as important as the other objectives of the fixed orthodontic treatment: The correction of the malocclusion and the re-education of the functions of the dento-maxillary apparatus (mastication, deglutition, respiratory function, speech and facial esthetics), as enamel damage can endanger the vitality of the tooth.

In conclusion, the present study demonstrated that the side cutter produced fractures of the ceramic brackets more frequently than the anterior bracket removal pliers. By contrast, the type of pliers used for the debonding procedures did not influence the amount of adhesive remaining on the tooth surface. After debonding, metallic brackets generated larger amounts of adhesive remaining on the enamel. Thus, through the OCT analysis of the enamel structure, the quality of the processes and materials used for manufacturing brackets can be increased. In the future, OCT examination may be used in vivo to facilitate orthodontic procedures in order to restore the tooth surface to its pre-treatment condition.

\section{Acknowledgements}

Not applicable.

Funding

No funding was received.

\section{Availability of data and materials}

The datasets used and/or analyzed during the current study are available from the corresponding author on reasonable request.

\section{Authors' contributions}

SMSP, MJT, FIM, AGN and ITD made substantial contributions to the conception and design of the study. SMSP, EO, AC, AIS, ITD and ESB made substantial contributions to the acquisition, analysis and interpretation of the data for the study. MJT, AC, ESB and ITD drafted the manuscript and revised it critically for important intellectual content. All authors reviewed the literature findings and critically revised the manuscript and approved the current form of the article in order to be submitted to the journal. MJT and ITD confirm the authenticity of all the raw data. All authors have read and approved the final manuscript.

\section{Ethics approval and consent to participate}

The present study was conducted according to the guidelines of the Declaration of Helsinki and approved by the Ethical Committee of the University of Medicine and Pharmacy of Craiova, Romania (decision reference no. 72/07.09.2020). Written informed consent was obtained from all subjects involved in the study.

\section{Patient consent for publication}

Not applicable.

\section{Competing interests}

The authors declare that they have no competing interests. 


\section{References}

1. Shimada Y, Sadr A, Sumi Y and Tagami J: Application of optical coherence tomography (OCT) for diagnosis of caries, cracks and defects of restorations. Curr Oral Health Rep 2: 73-80, 2015.

2. Hee MR, Puliafito CA, Wong C, Duker JS, Reichel E, Rutledge B, Schuman JS, Swanson EA and Fujimoto JG: Quantitative assessment of macular edema with optical coherence tomography. Arch Ophthalmol 113: 1019-1129, 1995.

3. Swanson EA, Izatt JA, Hee MR, Huang D, Lin CP, Schuman JS, Puliafito CA and Fujimoto JG: In vivo retinal imaging by optical coherence tomography. Opt Lett 18: 1864-1866, 1993.

4. Fercher AF, Hitzenberger CK, Drexler W, Kamp G and Sattmann H: In vivo optical coherence tomography. Am J Ophthalmol 116: 113-114, 1993.

5. Isenberg G and Sivak MV: Gastrointestinal optical coherence tomography. Technol Gastrointest Endosc 5: 94-101, 2003.

6. Chen Y, Aguirre AD, Hsiung PL, Huang SW, Mashimo H, Schmitt JM and Fujimoto JG: Effects of axial resolution improvement on optical coherence tomography (OCT) imaging of gastrointestinal tissues. Opt Express 16: 2469-2485, 2008.

7. Zhang J, Chen Z and Isenberg G: Gastrointestinal optical coherence tomography: Clinical applications, limitations, and research priorities. Gastrointest Endosc Clin N Am 19: 243-259, 2009

8. Welzel J: Optical coherence tomography in dermatology: A review. Ski Res Technol 7: 1-9, 2001.

9. Zhang K, Huang Y, Pradilla G, Tyler B and Kang JU: Real-time intraoperative full-range complex FD-OCT guided cerebral blood vessel identification and brain tumor resection in neurosurgery. In: Proceedings of the SPIE (International Society for Optics and Photonics). Photonic Therapeutics and Diagnostics VII, San Francisco, CA, pp1-8, 2011.

10. Srinivasan VJ, Radhakrishnan H, Jiang JY, Barry S and Cable AE: Optical coherence microscopy for deep tissue imaging of the cerebral cortex with intrinsic contrast. Opt Express 20: 2220-2239, 2012

11. Radhakrishnan H and Srinivasan VJ: Compartment-resolved imaging of cortical functional hyperemia with OCT angiography. Biomed Opt Express 4: 1255-1268, 2013

12. Srinivasan VJ, Mandeville ET, Can A, Blasi F, Climov M, Daneshmand A, Lee JH, Yu E, Radhakrishnan H, Lo EH, et al Multiparametric, Longitudinal optical coherence tomography imaging reveals acute injury and chronic recovery in experimental ischemic stroke. PLoS One 8: e71478, 2013.

13. Colston BW Jr, Everett MJ, Da Silva LB, Otis LL, Stroeve P and Nathel H: Imaging of hard- and soft-tissue structure in the oral cavity by optical coherence tomography. Appl Opt 37: 3582-3585, 1998.

14. Braz AK, Aguiar CM and Gomes AS: Evaluation of the integrity of dental sealants by optical coherence tomography. Dent Mater 27: e60-e64, 2011.

15. Garcez AS, Suzuki SS, Ribeiro MS, Mada EY, Freitas AZ and Suzuki H: Biofilm retention by 3 methods of ligation on orthodontic brackets: A microbiologic and optical coherence tomography analysis. Am J Orthod Dentofac Orthop 140: e193-e198, 2011.

16. Baek JH, Na J, Lee BH, Choi E and Son WS: Optical approach to the periodontal ligament under orthodontic tooth movement: A preliminary study with optical coherence tomography. Am J Orthod Dentofac Orthop 135: 252-259, 2009.

17. Newman GV: Epoxy adhesives for orthodontic attachments: Progress report. Am J Orthod 51: 901-912, 1965.

18. Oliver RG: A new instrument for debonding clean-up. J Clin Orthod 25: 407-410, 1991.

19. Bizheva K, Povazay B, Hermann B, Sattmann H, Drexler W, Mei M, Holzwarth R, Hoelzenbein $T$, Wacheck $V$ and Pehamberger H: Compact, broad-bandwidth fiber laser for sub-2-microm axial resolution optical coherence tomography in the 1300-nm wavelength region. Opt Lett 28: 707-709, 2003.

20. Hsieh YS, Ho YC, Lee SY, Chuang CC, Tsai JC, Lin KF and Sun CW: Dental optical coherence tomography. Sensors (Basel) 13: 8928-8949, 2013.

21. Brady DJ: Optical Imaging and Spectroscopy. In: Coherence imaging - 6.5 Optical coherence tomography. Wiley \& Sons, Inc., Hoboken, NJ, pp238-242, 2009.

22. Drexler W and Fujimoto JG: Optical Coherence Tomography. In: Dental OCT. Springer-Verlag, Berlin, Heidelberg, pp1166-1168, 2008.

23. Vo-Dinh T: Optical coherence tomography imaging. Chapter 13 In: Biomedical Photonics Handbook. CRC Press, Boca Raton, London, New York, NY, Washington, DC, pp22-24, 2003.
24. Sectakof PA and Selnes JE: Iatrogenic effects of ortodontic treatment. Ont Dent 71: 35-40, 1994.

25. Geiger AM, Gorelick L, Gwinnett AJ and Benson BJ: Reducing white spot lesions in orthodontic populations with fluoride rinsing. Am J Orthod Dentofac Orthop 101: 403-407, 1992.

26. Geiger AM, Gorelick L, Gwinnett AJ and Griswold PG: The effect of a fluoride program on white spot formation during orthodontic treatment. Am J Orthod Dentofac Orthop 93: 29-37, 1988

27. Demito CF, Vivaldi-Rodrigues G, Ramos AL and Bowman SJ: The efficacy of a fluoride varnish in reducing enamel demineralization adjacent to orthodontic brackets: An in vitro study. Orthod Craniofac Res 7: 205-210, 2004.

28. Osiac E, Bălseanu TA, Mogoantă L, Gheonea DI, Pirici I, Iancău M, Mitran SI, Albu CV, Cătălin B and Sfredel V: Optical coherence tomography investigation of ischemic stroke inside a rodent model. Rom J Morphol Embryol 55: 767-772, 2014.

29. Osiac E, Săftoiu A, Gheonea DI, Mandrila I and Angelescu R: Optical coherence tomography and Doppler optical coherence tomography in the gastrointestinal tract. World J Gastroenterol 17: $15-20,2011$

30. Chhibber A, Agarwal S, Yadav S, Kuo CL and Upadhyay M: Which orthodontic appliance is best for oral hygiene? A randomized clinical trial. Am J Orthod Dentofac Orthop 153: 175-183, 2018

31. Eissa OE, El Elshourbagy EA and Ghobashy SA: In vivo effect of a fluoride releasing adhesive on inhibition of enamel demineralization around orthodontic brackets. Tanta Dent J 10: 86-96, 2013.

32. Höchli D, Hersberger-Zurfluh M, Papageorgiou SN and Eliades T: Interventions for orthodontically induced white spot lesions: A systematic review and meta-analysis. Eur J Orthod 39: 122-133, 2017.

33. Fjeld M and Øgard B: Scanning electron microscopic evaluation of enamel surfaces exposed to 3 orthodontic bonding systems. Am J Orthod Dentofacial Orthop 130: 575-581, 2006.

34. Nawrocka A and Lukomska-Szymanska M: The indirect bonding technique in orthodontics-a narrative literature review. Materials (Basel) 13: 986, 2020.

35. Leão Filho JC, Braz AK, de Araujo RE, Tanaka OM and Pithon MM: Enamel quality after debonding: Evaluation by optical coherence tomography. Braz Dent J 26: 384-389, 2015.

36. Knösel M, Mattysek S, Jung K, Sadat-Khonsari R, Kubein-Meesenburg D, Bauss O and Ziebolz D: Impulse debracketing compared to conventional debonding. Angle Orthod 80: 1036-1044, 2010.

37. Drisko C: Oral hygiene and periodontal considerations in preventing and managing dentine hypersensitivity. Int Dent J 57 (Suppl): S399-S410, 2007.

38. Addy M: Dentine hypersensitivity: New perspectives on an old problem. Int Dent J 52 (Suppl 1): S367-S375, 2002.

39. Pretty IA, Pender N, Edgar WM and Higham SM: The in vitro detection of early enamel de- and re-mineralization adjacent to bonded orthodontic cleats using quantitative light-induced fluorescence. Eur J Orthod 25: 217-223, 2003.

40. Sinescu C, Negrutiu ML, Hughes M, Bradu A, Todea C, Rominu R, Dodenciu D, Laissuee PL and Podoleanu AG: Investigation of bracket bonding for orthodontic treatments using enface optical coherence tomography. Vol. 6991. SPIE Digital Library, pp69911M-1-69911M-5, 2008. doi: 10.1117/12.780701.

41. Rominu RO, Sinescu C, Pop DM, Hughes M, Bradu A, Rominu M and Podoleanu AG: En-face optical coherence tomography and fluorescence in evaluation of orthodontic interfaces. World Acad Sci Eng Technol 56: 641-644. 2009.

42. Janiszewska-Olszowska J, Tomkowski R, Tandecka K, Stepien P, Szatkiewicz T, Sporniak-Tutak K and Grocholewicz K: Effect of orthodontic debonding and residual adhesive removal on 3D enamel microroughness. PeerJ 4: e2558, 2016.

43. Kuskonmaz C, De Stefani A, Artioli G, Zanarini M, Bonetti GA, Bruno $\mathrm{G}$ and Gracco A: The use of the laser confocal scanning microscopy to measure resin remnants on customized lingual bracket. BMC Oral Health 20: 142, 2020

44. Ogiński T, Kawala B, Mikulewicz M and Antoszewska-Smith J: A clinical comparison of failure rates of metallic and ceramic brackets: A twelve-month study. Biomed Res Int 2020: 9725101, 2020.

45. Ravin JJ: Follow-up study of permanent incisors with enamel cracks as result of an acute trauma. Scand J Dent Res 89: 117-123, 1981.

46. Bevenius J, Lindskog S and Hultenby K: The micromorphology in vivo of the buccocervical region of premolar teeth in young adults. A replica study by scanning electron microscopy. Acta Odontol Scand 52: 323-334, 1994. 
47. Daprile G, Gatto MR and Checchi L: The evolution of buccal gingival recessions in a student population: A 5-year follow-up. J Periodontol 78: 611-614, 2007.

48. Zachrisson BU, Skogan O and Höymyhr S: Enamel cracks in debonded, debanded, and orthodontically untreated teeth. Am J Orthod 77: 307-319, 1980

49. Zarrinnia K, Eid N and Kehoe M: The effect of different debonding techniques on the enamel surface: An in vitro qualitative study. Am J Orthod Dentofac Orthop 108: 284-293, 1995.

50. Bishara SE and Trulove TS: Comparisons of different debonding techniques for ceramic brackets: An in vitro study. Part I. Background and methods. Am J Orthod Dentofac Orthop 98: 145-153, 1990.

51. Karamouzos A, Athanasiou AE and Papadopoulos MA: Clinical characteristics and properties of ceramic brackets: A comprehensive review. Am J Orthod Dentofacial Orthop 112: 34-40, 1997.
52. Winchester LJ: Bond strengths of five different ceramic brackets: An in vitro study. Eur J Orthod 13: 293-305, 1991.

53. Pinho M, Manso MC, Almeida RF, Martin C, Carvalho Ó, Henriques B, Silva F, Pinhão Ferreira A and Souza JCM: Bond strength of metallic or ceramic orthodontic brackets to enamel, acrylic, or porcelain surfaces. Materials (Basel) 13: 5197,2020

(i) (2) This work is licensed under a Creative Commons Attribution-NonCommercial-NoDerivatives 4.0 International (CC BY-NC-ND 4.0) License. 